\title{
Electrochemically functionalized carbon nanotubes for device applications
}

\author{
Kannan Balasubramanian and Marko Burghard \\ Received 26th November 2007, Accepted 4th February 2008 \\ First published as an Advance Article on the web 3rd March 2008 \\ DOI: $10.1039 / \mathrm{b} 718262 \mathrm{~g}$
}

The application range of carbon nanotubes (CNTs) has been significantly expanded by the advent of reliable chemical functionalization methods. This article surveys electrochemistry-based approaches that have been devised for the covalent and non-covalent modification of CNTs, and highlights their increasing importance in the development of nanoscale and macroscopic CNT devices. The primary focus is on electrochemical protocols for selective functionalization of CNTs according to their electronic properties, as well as the fabrication of various types of CNT-based sensors for gases and (bio)molecules.

\section{Introduction}

The prospects for the application of carbon nanotubes (CNTs) are multi-faceted ranging from reinforced composites to molecular-scale electronic devices. While most of the applications still remain a far-off dream, a number of such promises have been successfully realized such as field-emission displays ${ }^{1}$ and scanning probe tips. ${ }^{2}$ Moreover, CNTs have been successfully implemented as highly efficient conduction channels into fieldeffect transistors (FETs). However, although the first CNTFETs were demonstrated one decade ago, ${ }^{3,4}$ the integration of such devices as integral components of computers still remains to be achieved. While efforts are undertaken to reach this goal, optimized device architectures are constantly emerging ${ }^{5}$ and the basic understanding of the physics of CNT-FETs is steadily expanding. ${ }^{6,7}$ In this context, the development of reliable CNT chemical functionalization strategies has significantly contributed to the progress. ${ }^{8-11}$ The present review focuses on one specific type of functionalization method, namely the electrochemical route. After a brief introduction about carbon nanotubes in general and their reactivity, the available electrochemical functionalization schemes are outlined. The subsequent

Max-Planck-Institut fuer Festkoerperforschung, Heisenbergstrasse 1, D-70569 Stuttgart, Germany section is devoted to the fabrication of CNT-FETs through selective electrochemical elimination of metallic nanotubes. Following this, the application of electrochemically functionalized CNTs as detectors for gas molecules and as sensors for analytes in liquid solutions will be presented. The review concludes with future perspectives for devices based on electrochemically functionalized CNTs.

\section{Carbon nanotubes}

\subsection{Electronic and physical structure}

Carbon nanotubes are rolled-up graphene sheets occurring as single-wall (SWCNT) or multi-wall (MWCNT) cylinders. ${ }^{12}$ They have diameters from 0.4 up to a few nm, and their lengths range from a few nanometres up to several millimetres. Any single SWCNT can be specified by its chiral vector $(n, m)$, which in turn determines the tube's electronic structure. ${ }^{12}$ The diameter of an $(n, m)$ tube is given by $d=\frac{a}{\pi} \sqrt{\left(n^{2}+n m+m^{2}\right)}$, where the lattice constant $a$ is related to the nearest-neighbour bond distance $\left(a_{\mathrm{c}-\mathrm{c}}\right)$ between two carbon atoms through $a=\sqrt{3} a_{\mathrm{c}-\mathrm{c}}$ $=\sqrt{ } 3 \times 1.42 \AA=2.46 \AA$. In general, $(n, m)$-SWCNTs with $(n, m)$ being an integer multiple of 3 are metallic (m-SWCNTs) or semi-metallic, whereas all other tubes are semiconducting (s-SWCNTs). The band-gap of an s-SWCNT can be approximated to $0.8 \mathrm{eV} / d,{ }^{13}$ where $d$ is the diameter of the nanotube in

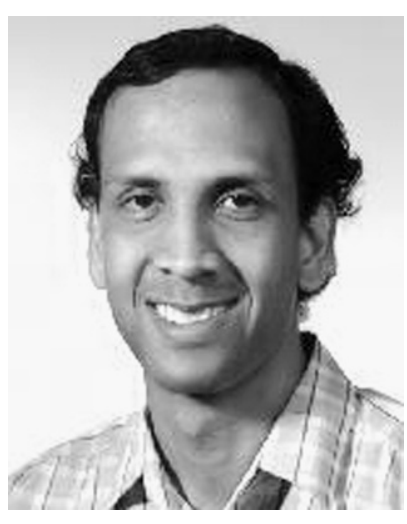

Dr Kannan Balasubramanian
Kannan Balasubramanian obtained his PhD in Nanostructure Physics from the EPFL, Switzerland in 2005 by working at the Max-Planck-Institute for Solid State Research, where he is currently leading a junior research group on Nanoscale Diagnostics. His interests include the use of functionalized $1 D$ nanostrucutures as sensors for applications in medical diagnosis.

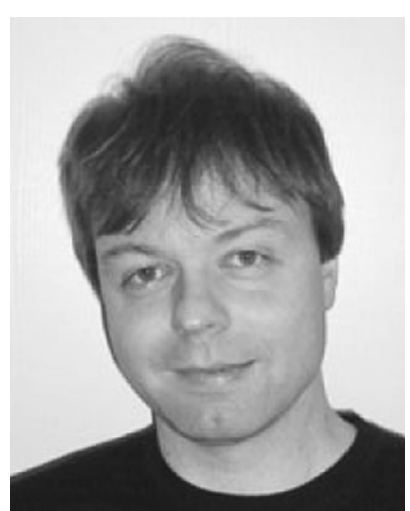

Dr habil. Marko Burghard
Marko Burghard received his PhD from the Institute for Physical Chemistry at the University of Tuebingen. Then he joined the Max-Planck Institute for Solid State Research, where he worked on thin organic films for applications in molecular electronics. Since 2000 his primary focus has been on the electrical and optical properties of different types of chemically functionalized nanowires. 


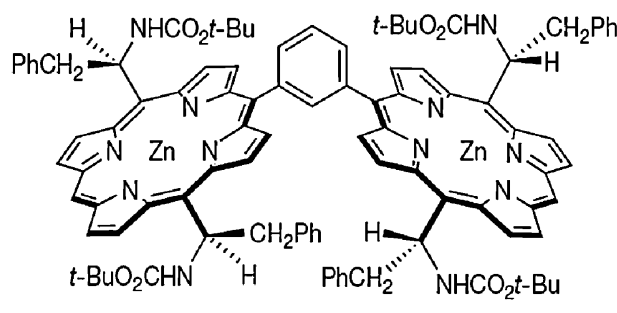

$(R)-1$
Mirror

image

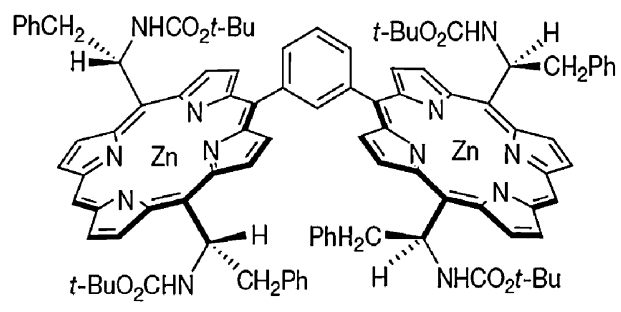

(S)-1

Fig. 1 Chemical structure of diporphyrin-based chiral nano-tweezers for the separation of left- and right-handed SWCNTs. They are simply designated $(R)-1$ and $(S)$-1, since all four sterogenic centers in both molecules have the same configuration. (Adapted with permission from ref. 17.)

nm. Most of the commercially available nanotube raw materials contain tubes with a distribution of diameters and a corresponding variation of physical properties. Hence, much recent work has been devoted toward separating the nanotubes according to their chirality or electronic structure. Enrichment of single chirality SWCNTs has recently been achieved by single-stranded DNA that helically wraps around the tubes, combined with a two-step separation involving size exclusion and ion exchange chromatography. ${ }^{14}$ In this manner, $(9,1)$ tubes could be effectively purified from $(6,5)$ tubes of almost identical diameter. A related approach comprises the chirality-selective extraction of SWCNTs by wrapping of fluorene-based polymers, which afforded high-purity $(7,5)$ nanotubes. ${ }^{15,16}$ As a further exciting development, it has been possible to separate right- from lefthanded SWCNTs with the aid of appropriately designed chiral diporphyrin molecules (Fig. 1) capable of forming nanotube complexes of different stabilities. ${ }^{17}$

\subsection{Chemical reactivity}

The sites of highest chemical reactivity within carbon nanotubes are the caps, which have a fullerene-like structure. Chemical functionalization of CNT tips has been performed mainly on the basis of oxidative treatments. ${ }^{18,19}$ As a general rule, CNT purification by oxidation yields tubes with oxygen-containing functional groups (predominantly carboxylic acid) at both the sidewall and the tube endings. These groups can then be used to link molecules via, e.g., amide bond formation. ${ }^{20}$

The curvature of the nanotube sidewall renders covalent bond formation to the $\mathrm{sp}^{2}$ carbon framework more favorable than for planar graphene. ${ }^{21}$ On this basis, a range of sidewall modification protocols have been established, most notably involving the addition of carbenes ${ }^{22,23}$ and azomethine ylides. ${ }^{24,25}$ Meanwhile, there exist several experimental studies which reveal that the (exohedral) chemical reactivity rises with increasing curvature of the wall. ${ }^{26-28}$ This dependency has been attributed to curvature-induced strain that originates from pyramidalization of the $\mathrm{sp}^{2}$-hybridized carbon atoms and the misalignment of $\pi$-orbitals. ${ }^{29-31}$ It is noteworthy that for certain types of nanotubes, the binding energy may increase instead of decrease when going from smaller- to larger-diameter tubes. One example is the chemisorption of hydrogen on zigzag tubes, as predicted by a recent theoretical study. ${ }^{32}$ For a more comprehensive description, the direction dependence of curvature has to be taken into account. ${ }^{33}$
Metallic and semiconducting SWCNTs display different reactivity toward covalent functionalization, as has been demonstrated for hydrogen peroxide-mediated oxidation, ${ }^{34}$ addition reactions like the coupling of aromatic diazonium ${ }^{8}$ or nitronium ${ }^{9}$ ions, or osmylation. ${ }^{35}$ In general, m-SWCNTs, due to their larger propensity for both donating and accepting electrons, exhibit a higher reactivity than their semiconducting counterparts. ${ }^{36}$ However, it should be kept in mind that doping (as a result of, e.g., the purification procedure) can render the reactivity of semiconducting tubes comparable to that of the metallic ones. ${ }^{37}$ This may explain experimental findings that the functionalization is selective toward smaller diameter tubes, but largely independent of the tubes' electronic character. ${ }^{38}$

Like the chemisorption energy, the binding position of reactive atoms or groups can depend on the type of nanotube. For instance, while in case of armchair tubes pairs of hydrogen atoms have been theoretically predicted to preferably attach to adjacent positions, ${ }^{39,40}$ calculations on zigzag tubes indicate alternate carbon sites to be most favorable. ${ }^{32}$ Interestingly, it has been found that Clar's valence bond model ${ }^{41}$ allows successful prediction of the preferred pattern of covalently bonded hydrogen atoms on CNTs. ${ }^{42}$

Defects such as vacancies and pentagon-heptagon pairs or Stone-Wales (SW) defects (Fig. 2) profoundly alter the chemical reactivity of the SWCNT sidewall. ${ }^{43-46}$ Their strong relevance is

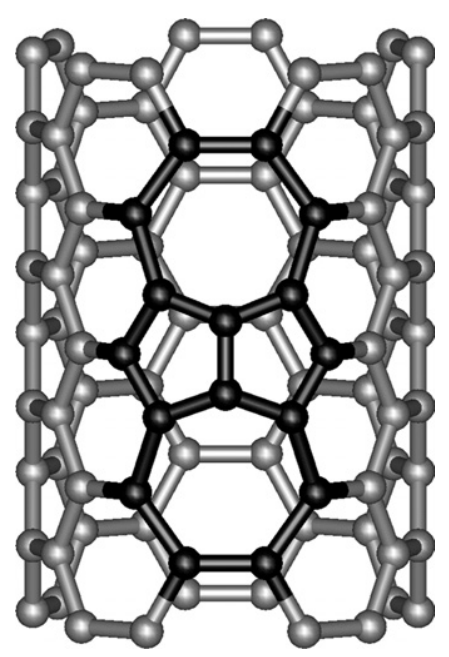

Fig. 2 Schematic depiction of a pentagon-heptagon pair (Stone-Wales defect) in the sidewall of a carbon nanotube. 
apparent from the fact that approximately $2 \%$ of the carbon atoms in SWCNTs occur in non-hexagonal rings. ${ }^{47}$ The presence of defects usually leads to locally enhanced reactivity. For example, according to theory the addition of methylene $\left(\mathrm{CH}_{2}\right)$ is significantly more favorable at SW defects than at the intact sidewall. $^{48}$ However, there can be pronounced differences between the various defect-associated addition sites. ${ }^{49}$ In particular, the central 7,7 ring fusion at SW defects in armchair tubes has been found by theory to be less reactive than the sidewall. ${ }^{50}$

Covalent sidewall functionalization strongly affects the electronic properties of the nanotubes as a consequence of the reduced number of delocalized $\pi$-electrons. With increasing functionalization degree, metallic SWCNTs first assume semiconducting character ${ }^{51}$ until they eventually become insulating. ${ }^{52}$ It has been shown for diazonium-functionalized metallic SWCNTs that annealing at $500{ }^{\circ} \mathrm{C}$ removes a large fraction of the attached aryl groups and thus partially restores their original conductivity. ${ }^{53}$ While reliable experimental data concerning the location and orientation of the appended moieties are not yet available, several theoretical investigations have addressed this topic. $^{54-57}$ A special case may be the $[2+1]$ cycloaddition of species like $\mathrm{CH}_{2}$ or $\mathrm{NH}$, which has been predicted to preserve the electronic properties of the nanotubes. ${ }^{58}$ Recovery of $\mathrm{sp}^{2}$ hybridization through bond cleavage between adjacent sidewall carbons has been implicated to explain this characteristic. A first confirming hint has recently been gained by experiments on SWCNTs modified by cyclopropanation via the Bingel reaction. ${ }^{59}$

\section{Electrochemical functionalization}

\subsection{Strategies}

CNTs are ideally suited for electrochemistry-based functionalization schemes due to their good electrical conductivity, their low capacitance which arises due to their one-dimensional nature, and the thickness of the electrochemical double layer being comparable to the diameter of the nanotube. ${ }^{60}$ There are a range of experimental indications that CNT surfaces exhibit fast electron transfer rates for various redox systems, comparable to the edge planes of pyrolytic graphite. ${ }^{61,62}$ The first experiments using individual MWCNTs as electrodes demonstrated that the limiting electrochemical current is a function of the length of the nanoscale electrode. ${ }^{63}$ This electrode was fabricated in a facile manner by attaching an individual MWCNT tube to a Pt tip with the aid of silver paste. Similar electrochemical characteristics have been observed at individual SWCNT electrodes fabricated by nanolithography. ${ }^{64}$

Bulk CNT electrodes have been fabricated in a number of ways, ${ }^{65}$ including the preparation of a bucky-paper electrode through vacuum filtration of a nanotube suspension, ${ }^{66}$ or the deposition of a thick CNT network onto a glassy carbon or a metal electrode. ${ }^{67}$ The electron transfer kinetics at such electrodes have been shown to depend on the length and orientation of the nanotubes. Specifically, the electron transfer between the underlying metal electrode and a redox couple in solution was found to be 40 times faster through vertically aligned tubes than through randomly dispersed SWCNTs. ${ }^{68}$ This difference indicates that in the random network the electron transfer is impeded by the more complicated pathway presumably involving intertube junctions. Moreover, the electron transfer rate through the array varied inversely with the average tube length, which has been rationalized on the basis of the nanotubes acting as a resistive element in the circuit. The latter finding could help to clarify the discrepancy between earlier studies on this topic. ${ }^{69,70}$

Electrochemical functionalization involves the creation of an active species from a precursor in the vicinity of a working electrode (WE) ${ }^{71}$ The active species that is formed through charge transfer with the WE (nanotube here) often has a tendency to react further with the precursor or to self-polymerize yielding a coating on the nanotube surface. Depending on the choice of precursor and electrochemical conditions, such polymerization may or may not be accompanied by the formation of covalent bonds to the carbon framework of the nanotubes. ${ }^{52}$ The electrochemical coupling can be achieved using different methods. Most common is the potentiostatic technique, wherein a constant potential is applied over an extended period of time. The appropriate potential to be applied is estimated by performing cyclic voltammetry. ${ }^{71}$ Electrochemical modification can also be performed galvanostatically where a constant current density is applied over a desired period of time. In the case of bulk electrodes, where usually the nanotubes are in exclusive contact with the solution, complete voltammetric scans can be studied. ${ }^{72}$ When using this method with single SWCNTs, special preparation steps are required to ensure that the contacting electrodes and pads do not come in contact with the solution. ${ }^{73,74}$ The advantage of performing complete voltammetric scans is that the corresponding amperometric signal measured during the functionalization procedure provides information on the underlying coupling mechanism. ${ }^{75}$

In the following, the various electrochemical functionalization schemes for CNTs are classified under metal nanoparticle decoration, as well as covalent and non-covalent attachment of organic or inorganic moieties.

\subsection{Metal particle decoration}

Electrochemistry provides a simple but efficient route for the decoration of nanotubes with metal nanoparticles. In such an experiment, a metal salt in solution is reduced by application of an appropriate potential. Electrodeposition offers several advantages over alternative methods such as metal evaporation or deposition of pre-formed colloid particles, most importantly good control over the size and density of the particles. In addition, electrochemically decorated particles are in intimate contact with the carbon nanotubes in comparison to metal colloids deposited from solution, which is important for some applications. ${ }^{76,77}$ CNTs decorated with transition metals like platinum or palladium are interesting as catalysts with high surface $\operatorname{area}^{78}$ or as chemical sensors (see Section 5).

As a representative example, SWCNTs with electrodeposited gold nanoparticles are depicted in Fig. 3. In Table 1, a survey of electrodeposition parameters used for decorating CNTs with different metals is provided. In contrast to platinum, palladium and nickel, the electrodeposition of silver and gold usually requires stabilizers in order to obtain regular particles. ${ }^{76,77}$ Silver nanoparticle deposition onto SWCNTs has also been reported in 


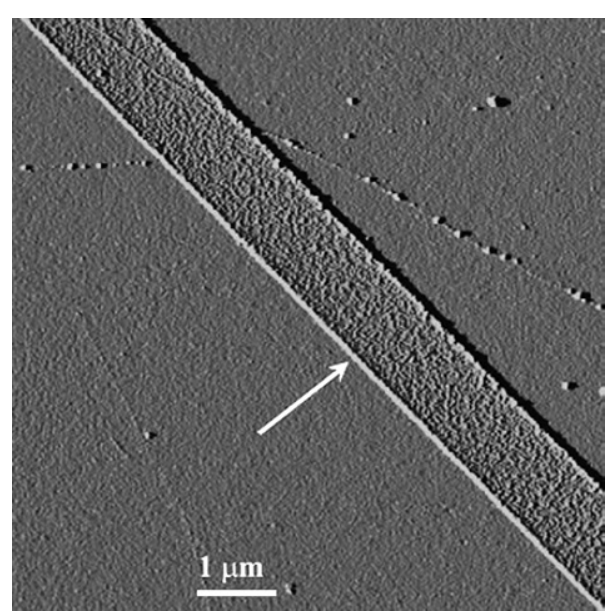

Fig. 3 Atomic Force Microscope (AFM) amplitude image of two contacted SWCNTs electrochemically decorated with a low density of Au nanoparticles. The tube on the lower left side that is not in contact with the electrode remains unmodified. The arrow points towards the electrode used for contacting the nanotubes. The electrochemical modification was carried out in an aqueous solution of $\mathrm{KAuCl}_{4}$ with (poly)vinylpyrrolidone as the stabilizer and $\mathrm{LiClO}_{4}$ as the supporting electrolyte.

the absence of a stabilizer. ${ }^{75}$ The size and distribution of the nanoparticles can in general be controlled by the magnitude of the applied potential and the concentration of the metal salt in solution. However, the growth kinetics can vary substantially from one metal to another. ${ }^{75}$ For example, Ag nucleates much faster than $\mathrm{Pt}$ on the bare nanotube and thus by varying the time of deposition the density of $\mathrm{Ag}$ nanoparticles can be controlled, while with Pt nanoparticles increasing the deposition time results in bigger clusters. There is convincing experimental evidence that the particles preferentially nucleate at defect sites. For example, defects introduced by gentle oxygen plasma or mild acid treatment have resulted in an increased density of nanoparticles on a SWCNT network. ${ }^{79}$ In another study, nickel has been electrodeposited in a controlled manner onto individual SWCNTs. ${ }^{80}$ After oxidative dissolution and re-deposition of $\mathrm{Ni}$, the particles were found at exactly the same positions as before. Selective decoration of the nanotube ends (Fig. 4) has also been reported, albeit requiring isolation of the sidewalls from the solution by using either a patterned mask ${ }^{81}$ or vertical arrays of nanotubes. ${ }^{82}$

\subsection{Covalent functionalization}

The development of covalent electrochemical functionalization schemes for CNTs has largely built upon earlier work on carbon-based electrodes like glassy carbon or highly ordered pyrolytic graphite (HOPG) ${ }^{83}$ The major electrochemical protocols described so far are CNT oxidation, ${ }^{84-86}$ nitration, ${ }^{87}$ hydrogenation, ${ }^{88}$ halogenation, ${ }^{89}$ and addition of phenyl radicals $^{72}$ (Scheme 1). In general, the higher curvature of SWCNTs renders them more amenable to covalent modification than MWCNTs. Functionalization degrees exceeding 5\% have been

Table 1 Representative examples of various parameters used for decorating SWCNTs with metal nanoparticles

\begin{tabular}{|c|c|c|c|c|c|}
\hline Nanoparticle & Metal salt & Stabilizer & Supporting electrolyte & Solvent & References \\
\hline $\mathrm{Pd}$ & $\mathrm{Na}_{2}\left(\mathrm{PdCl}_{4}\right)$ & - & $\mathrm{LiClO}_{4}$ & Ethanol & 153 \\
\hline $\mathrm{Pt}$ & $\mathrm{H}_{2}\left(\mathrm{PtCl}_{6}\right)$ & - & $\mathrm{LiClO}_{4} / \mathrm{HClO}_{4}$ & Ethanol & 75 \\
\hline $\mathrm{Ag}$ & $\mathrm{AgCN}$ & $\mathrm{K}_{4} \mathrm{P}_{2} \mathrm{O}_{7}$ & $\mathrm{KCN}$ & Water & 76,77 \\
\hline & $\mathrm{AgNO}_{3}$ & - & $\mathrm{KNO}_{3}$ & Water & 79 \\
\hline $\mathrm{Ni}$ & $\mathrm{NiSO}_{4}$ & - & $\mathrm{Na}_{2} \mathrm{SO}_{4}$ & Water & 80 \\
\hline
\end{tabular}
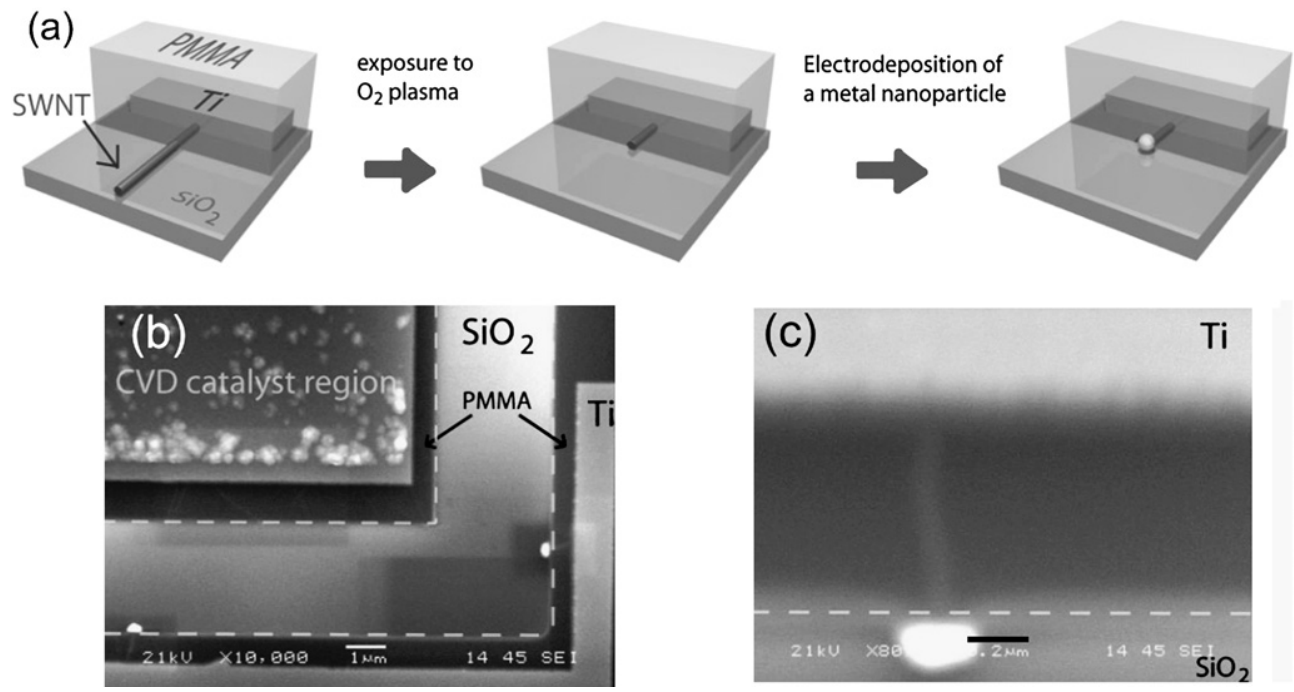

Fig. 4 (a) Scheme showing the preparation of a metal nanoparticle at the end of a single SWCNT. (b) and (c) SEM images showing the metal nanoparticle formed at the exposed end of a single SWCNT (adapted with permission from ref. 81). 

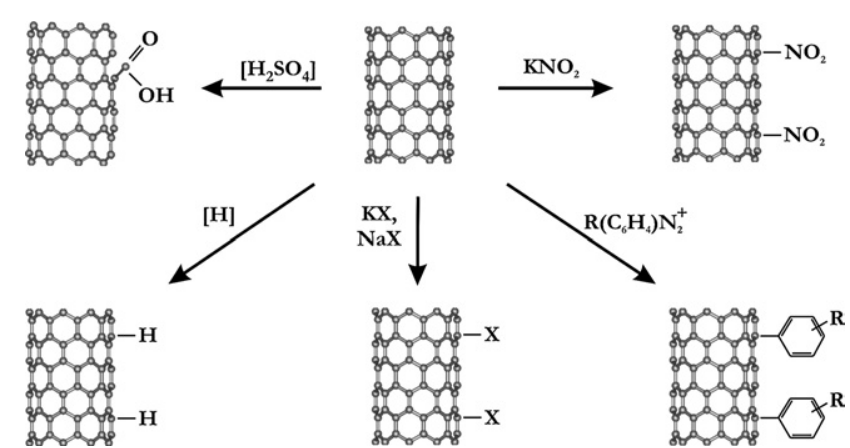

Scheme 1 Scheme showing the major electrochemical functionalization routes for carbon nanotubes.

found, ${ }^{72}$ although considerable variations among the obtained products may exist. Since the covalent functionalization at the same time opens the nanotube tips, the resulting material exhibits an increased surface area. ${ }^{84,85}$ In the case of anodic reactions, the introduction of oxygenated functional groups like $-\mathrm{OH}$ or $-\mathrm{COOH}$ typically occurs as a significant side reaction. ${ }^{89}$ Single covalent bonding events at the nanotube sidewall could be monitored by in situ measurements of the electrical conductance of individual SWCNTs during their electrochemical oxidation within an aqueous electrolyte. ${ }^{74}$ This study provided evidence that covalent bonding events can directly occur at the intact sidewall, rather than requiring a defect site for the bond formation. Electrochemical oxidation of MWCNTs has been shown to strongly improve their electrochemical reactivity. ${ }^{90}$

The functionalization scheme based upon benzene diazonium salts is compatible with a wide range of substituents on the phenyl ring. ${ }^{52,72,91,92}$ Spectroscopic studies suggest that extensive diazonium coupling leads to the formation of aryl chains grafted to the CNT sidewall. ${ }^{91}$ Substituted phenyl groups electrochemically appended to CNTs have been utilized as anchors for the subsequent attachment of metal nanoparticles, ${ }^{93}$ the grafting of poly(methyl methacrylate) and polystyrene brushes via atom transfer radical polymerization, ${ }^{94}$ as well as the immobilization of hydrogenase ${ }^{95}$ and DNA molecules. ${ }^{96}$ There are also reports of covalent attachment of polyaniline under certain conditions of aniline electropolymerization onto SWCNTs, without the need for such anchors. ${ }^{97,98}$

\subsection{Non-covalent functionalization}

The non-covalent electrochemical modification of CNTs has been accomplished through four major approaches, namely (i) electropolymerization of organic precursor molecules onto CNTs, (ii) electrodeposition of inorganic compounds, (iii) co-electrodeposition of CNTs and a polymer matrix onto a solid support, and (iv) electrophoretic deposition of pre-formed moieties.

It should be emphasized that in the electrografting experiments described below, non-covalent attachment to the CNTs is a plausible scenario. However, in several cases the obtained products have been insufficiently characterized, such that (partial) covalent anchoring of the polymers cannot be excluded. ${ }^{99}$ Some hints toward covalent modification have been obtained for, e.g., the oxidative polymerization amines, ${ }^{100}$ as well as the electrografting of polyacrylates ${ }^{101}$ or poly $(N$-vinylcarbazole). ${ }^{102,103}$ However, further studies are required to fully clarify this aspect.

3.4.1 Electropolymerization approach. There are a range of publications dealing with the electropolymerization of appropriate monomers onto CNT thin film or bucky-paper electrodes. The most relevant polymers that have been used to coat CNTs in this manner are depicted in Scheme 2. In the initial stage, motivated by the wealth of data available on the corresponding conducting polymers, the experiments were focused on the electropolymerization of aniline ${ }^{104-106}$ and pyrrole. ${ }^{107,108}$ More recently, polymer coatings obtained via electropolymerization of $o$-phenylenediamine onto oxidatively pre-treated MWCNTs were found to strongly interact with the nanotubes via oxygencontaining functional groups (presumably $-\mathrm{COOH}) .{ }^{109}$ This interaction has been interpreted as the origin of the enhanced polymer deposition rate in comparison to a bare glassy carbon electrode (GCE). It has been speculated that the created cationic radicals preferentially attach to the acidic sites on the nanotubes, thereby greatly increasing the number of nucleation sites for the polymerization reaction. This behaviour is different from that of polypyrrole, for which no facilitated grafting has been observed. ${ }^{110}$

Apart from polyaniline and polypyrrole, the electrodeposition of a few other polymers has been performed. Electrografting of polyacrylonitrile onto MWCNTs yielded coatings that are stable up to $\sim 250{ }^{\circ} \mathrm{C}$, at which temperature the polymer undergoes exothermic cyclization. ${ }^{99}$ However, only a low grafting ratio of $\sim 0.3$ (i.e., weight ratio of polymer to $\mathrm{CNTs}$ ) was found in this work. More homogeneous coatings were obtained via electropolymerization of fluorene onto oxidatively modified SWCNTs, ${ }^{110}$ carbazole onto SWCNTs, ${ }^{111}$ and $N$-vinyl-carbazole onto SWCNTs or MWCNTs. ${ }^{102,103}$ An interesting recent work has addressed a major problem in the electrochemical functionalization of large CNT ensembles, namely the fact that the reaction is often limited to a thin surface layer with a thickness of just a few
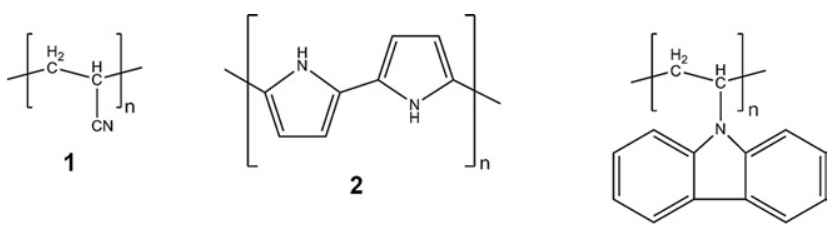

3<smiles></smiles>

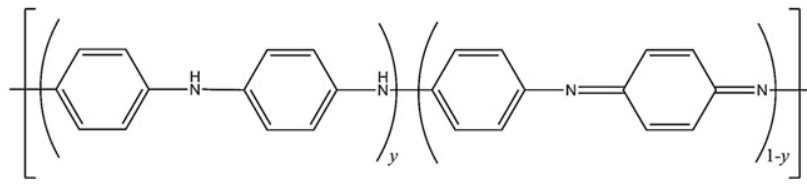

Scheme 2 The chemical structure of common polymers used for electrografting onto carbon nanotubes: 1-polyacrylonitrile, 2-polypyrrole, 3 -poly- $N$-(vinyl-carbazole), 4 -poly-(o-phenylenediamine) 5 -polyaniline. 


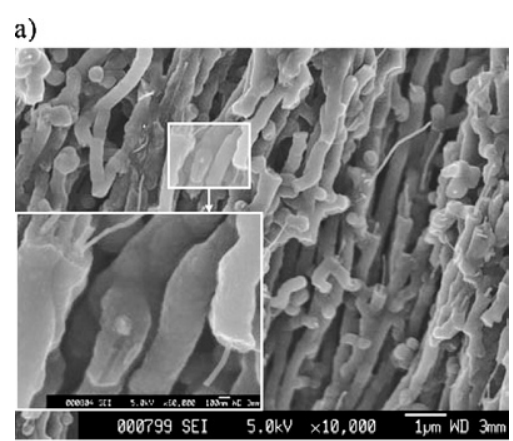

b)

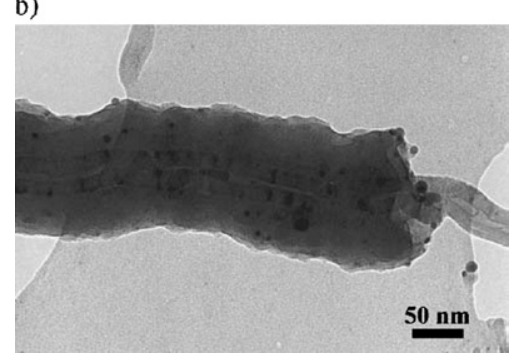

Fig. 5 (a) SEM image of aligned MWCNTs electrochemically coated by a layer of polypyrrole; (b) TEM image of an individual modified nanotube, revealing a thickness of the polymer sheath of approximately 30 $\mathrm{nm}$. (Adapted with permission from ref. 201.)

micrometres. It has been demonstrated that by embedding the tubes in an ionic liquid, efficient polymer electrografting can be achieved throughout the CNT network. ${ }^{101}$

Besides ensembles composed of randomly oriented CNTs, vertically aligned CNT arrays have been used as electrodes in electrografting procedures (Fig. 5). The latter type of electrode offers the advantage of a large surface area, which is beneficial for applications in, e.g., chemical sensors or photovoltaic cells. The first such report involved the electropolymerization of pyrrole, which yielded aligned polypyrrole-sheathed MWCNTs. ${ }^{104}$ Free access of the monomer requires proper control over the CNT density, which results in uniform polymer coatings reaching thicknesses of several tens of nanometres. ${ }^{112}$ Other polymers that have been electrodeposited onto vertical CNT arrays are polyaniline, ${ }^{113,114}$ poly(o-anisidine) $)^{115}$ and polymethacrylonitrile. ${ }^{116}$

In contrast to bulk CNT electrodes, studies on the coating of individual CNTs with non-covalently attached polymers are rare. This task has been achieved via electropolymerization of substituted aromatic amines like 4-amino-benzylamine. ${ }^{117}$ AFM investigations revealed that the electropolymerization procedure offers a high degree of controllability over the thickness of the polymer layer by adjusting the deposition time and potential, and is capable of yielding closed coatings even for polymer thicknesses as small as 3-4 nm. Moreover, the combination of Raman spectroscopy and electrical conductivity measurements has proven highly valuable for confirming the largely unperturbed electronic character of the modified tubes. ${ }^{52}$

3.4.2 Electrodeposition of inorganic compounds. Compared to organic polymers, only a little work has been performed on the electrodeposition of inorganic materials onto CNTs. One example is the cathodic deposition of cadmium sulfide onto
MWCNTs. ${ }^{118}$ Further to this, there are reports of electrodeposition of Prussian blue ${ }^{119}$ and molybdenum oxides onto MWCNTs. ${ }^{120}$ In the first two cases, the nanotubes were pretreated by oxidation in order to provide them with appropriate anchor groups.

3.4.3 Electrodeposition of mixed CNT-polymer films. Initial studies along this direction comprised the polymerization of aniline or polypyrrole within aqueous solutions containing dispersed CNTs which act as a dopant for the formed polymers. ${ }^{\mathbf{1 2 1 , 1 2 2}}$ The resulting composite films often showed a porous structure imparting a high surface area. ${ }^{123}$ Later, polypyrroleCNT composite nanowires were synthesized by a template-based approach, wherein the polymer is electroplated into the pores of an alumina membrane in the presence of carboxylated CNTs. ${ }^{124}$ Moreover, aligned polypyrrole-CNT composite films were fabricated with the aid of an ionic surfactant as the electrolyte. ${ }^{125}$ In the latter study, electric-field induced orientation of the micelle-enclosed CNTs has been put forward as a possible mechanism for tube alignment during the polymerization process (Fig. 6). Very recently, electrodeposition has been used to produce chiral polyaniline-MWCNT composite films whose optical activity can be tuned by the choice of electrode material and nanotube concentration. ${ }^{\mathbf{1 2 6}}$

Various strategies have been pursued to enhance the interaction between the conducting polymer matrix and the nanotubes. As one possibility, nanotubes non-covalently modified by adsorption of dodecylbenzene ${ }^{127}$ or 1-pyrene sulfonic acid ${ }^{128}$ have been employed. Alternatively, the CNTs were covalently functionalized with amino groups ${ }^{\mathbf{1 2 9 , 1 3 0}}$ or $\operatorname{poly}(m$-aminobenzene sulfonic acid) ${ }^{\mathbf{1 3 1}}$ in order to provide anchors for the polymer. A third strategy is based upon covalent linkage of the monomer to the CNTs prior to electropolymerization. ${ }^{132-136}$

Also non-redox processes have been developed for the fabrication of polymer-CNT composite films, as exemplified by the electrodeposition of chitosan-MWCNT films. ${ }^{137}$ The underlying mechanism here is a $\mathrm{pH}$ increase near the cathode surface as

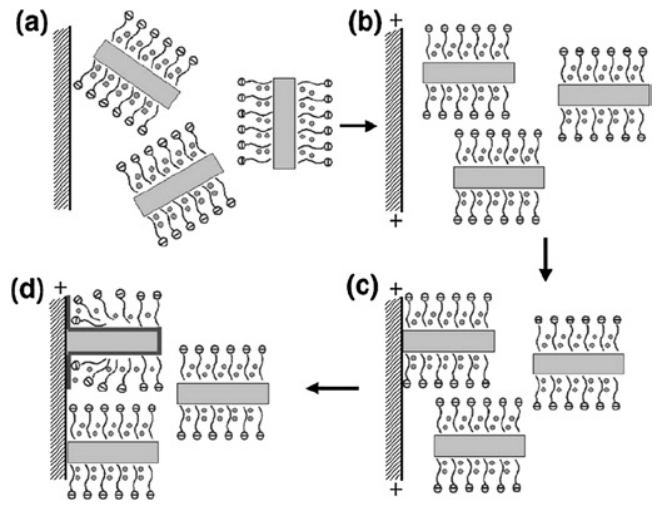

Fig. 6 Schematic illustration of a possible mechanism for the perpendicular orientation of nanotubes during the electrodeposition of conducting polymer-CNT composite films. The micelle-encased tubes, which are disordered in the absence of an electric field (a), become aligned when an electric field is applied (b). After depositing on the electrode (c), electropolymerization of the monomer occurs at the electrode and nanotube surface if a sufficiently high potential is applied (d). (Adapted with permission from ref. 125.) 
a consequence of proton reduction, which causes precipitation of the chitosan.

3.4.4 Electrophoretic deposition. Electrophoretic coating, an approach that has received the smallest attention so far, has been used to deposit protonated, positively charged titanium dioxide clusters in high density along vertically aligned MWCNTs. ${ }^{138}$ The thickness of the resulting homogeneous $\mathrm{TiO}_{2}$ coatings could be controlled by the applied voltage and deposition time.

\section{Field-effect transistors}

A major impetus for increasing research in the field of CNTs was the fabrication of field-effect transistors (FETs). ${ }^{3,4}$ In fact, the realization of transistors with just a nanometre-wide channel was expected to further stimulate the miniaturization drive in information technologies. However, this expectation has not yet been fulfilled, which is largely due to the fact that CNTsunlike conventional semiconductor materials - are available mostly as a mixture of $\mathrm{m}$ - and s-SWCNTs. Hence, for routine fabrication of CNT-FETs, the m-SWCNTs need to be eliminated either before or after their implementation into a device. Within the first approach, different chemical methods have been used which exploit for instance the differing interaction between m- and s-SWCNTs with various polymers, ${ }^{15}$ although the attained enrichment factors are still well below $100 \%$. More promising separation efficiencies have been attained by physical methods like dielectrophoresis ${ }^{139}$ and density gradient centrifugation, ${ }^{140}$ however, it is more difficult to scale-up these procedures.

The most common technique employed for eliminating $\mathrm{m}$-SWCNTs at the device level involves destruction of the m-SWCNTs by passing a high current through the CNT ensemble. ${ }^{141}$ Here a back-gate is required in order to switch the s-SWCNTs to the OFF state, in order to ensure that the current is exclusively carried by the metallic tubes. Another selective elimination method applicable to CNT devices is electrochemical functionalization, which has been demonstrated in two different ways. In the first variant, the hysteresis of back-gated SWCNTFETs is utilized to bring the s-SWCNTs within a network to the OFF state by sweeping the back-gate voltage appropriately. ${ }^{\mathbf{1 4 2}}$
Subsequently, the metallic tubes are strongly modified through electrochemical diazonium coupling, whereupon their resistance is increased by more than three orders of magnitude due to the covalent attachment of a high density of phenyl residues ( $c f$. Section 3.3). The resulting network shows a semiconducting behaviour, and its conductance can be tuned over 6 orders of magnitude as shown in Fig. 7. The second variant involves the elimination of m-SWCNTs without the use of a back-gate, exploiting the difference in electrochemical reactivity between $\mathrm{m}$ - and s-SWCNTs. ${ }^{143}$ Its underlying principles are best conveyed by first presenting the concepts of liquid-gating and in situ monitoring of the tube conductance.

\subsection{Liquid-gating}

While performing electrochemistry, the potential of the working electrode connected to the material of interest (CNTs in the present case) is adjusted with respect to a well-defined potential at a reference electrode (RE). Thus varying the potential at the $\mathrm{RE}$ results in a modulation of the electrochemical potential of the CNTs. If the WE comprises an individual s-SWCNT, this variation of the electrochemical potential would lead to a change in the filling of the energy levels and correspondingly alter the conductance of the nanotube. ${ }^{60}$ If the other end of the tube is connected to a fourth electrode (apart from WE, RE and CE), it is possible to measure the conductance of the contacted tube in dependence of the voltage applied to the RE. In this manner, it is possible to gate the nanotube in a liquid medium, and the device functions as an electrochemical field-effect transistor (EC-FET). The gating effect in such a device relies upon the formation of an electrochemical double layer (Helmholtz layer) at the nanotube-electrolyte interface upon application of a liquid-gate voltage at the RE. While the conception of an EC-FET does not appear promising for semiconductor electronics, it offers a number of other advantages including highly efficient gate coupling as well as the possibility of fabricating FET-based nanoscale sensors in liquids.

Fig. 8 shows the gate dependence of conductance of a m-SWCNT and a s-SWCNT in both back-gated and liquidgated configurations. For the liquid-gated curves the potentials at the bottom scale refer to the voltage applied to the gate (RE) referenced to the nanotube, following the convention for
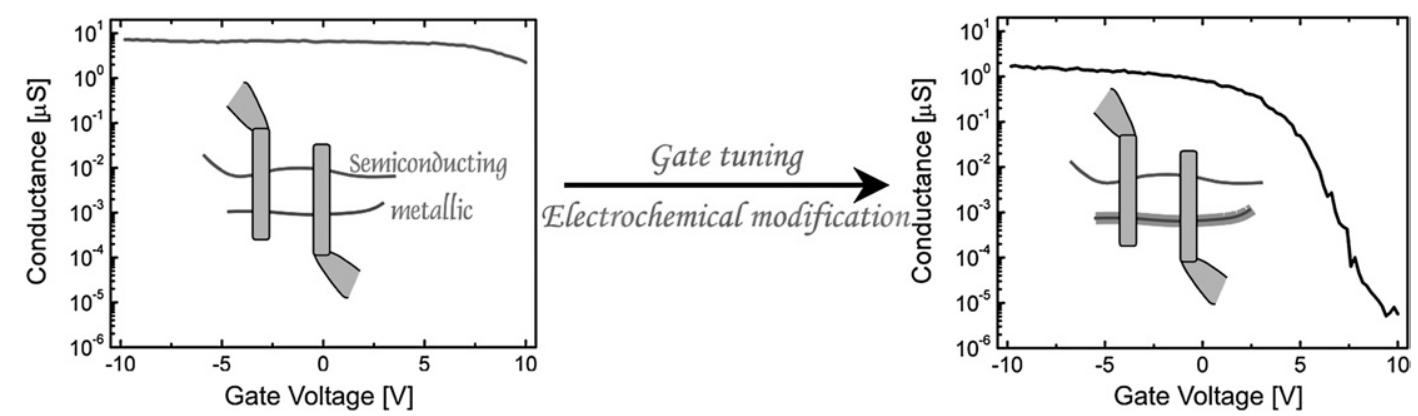

Fig. 7 Back-gate dependence of a sparse SWCNT network before and after electrochemical modification. Initially the device behaves as a metal with a very low modulation of conductance. The network is electrochemically modified in a solution of 4-nitrobenzenediazonium tetrafluoroborate in DMF $\left(0.1 \mathrm{M} \mathrm{LiClO}_{4}\right.$ as supporting electrolyte), after sweeping the back-gate voltage to bring the s-SWCNTs to the OFF state. In this manner, m-SWCNTs are exclusively covalently modified and become highly resistive. This results in a semiconducting network, whose conductance can be varied over 6 orders of magnitude with the gate voltage. (Adapted with permission from ref. 142.) 

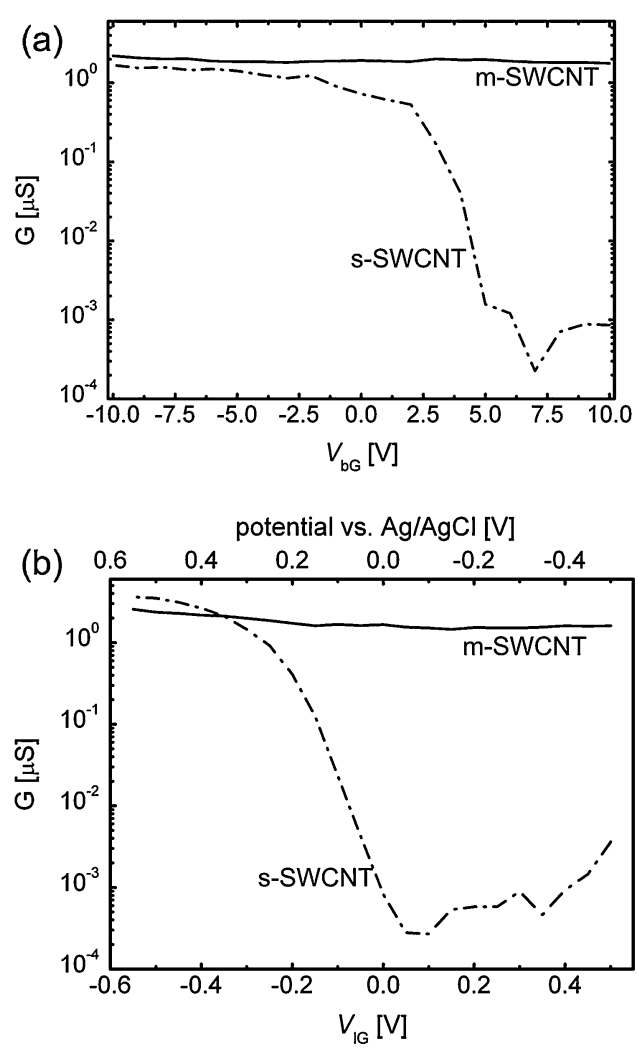

Fig. 8 (a) Gate dependence of conductance for an individual $\mathrm{m}$ - and s-SWCNT as a function of the back-gate voltage. (b) Liquid-gate dependence of conductance for the same $\mathrm{m}$ - and s-SWCNTs in water, using an $\mathrm{Ag} / \mathrm{AgCl}$ electrode as the gate. The lower scale refers to the voltage at this gate electrode, while the upper scale denotes the potential at the nanotube with respect to the $\mathrm{Ag} / \mathrm{AgCl}$ reference (electrochemical convention).

FETs. The top scale displays the potential in a convention common in electrochemical experiments, where the potential at the nanotube is referenced to the RE. For the remainder of this review, this electrochemical convention will be used for the gate potentials. From the curves it is apparent that electrochemical gating in a liquid is much more efficient than back-gating, with the liquid-gate voltage range being an order of magnitude smaller and the sub-threshold slope much steeper. The improved performance is a consequence of the difference in gate capacitances. The thickness of the electrochemical double layer is of the order of a few $\mathrm{nm}$ (capacitance: $2000 \mathrm{pF} \mathrm{m}^{-1}$ ), in comparison to $100 \mathrm{~nm}$ in case of the $\mathrm{SiO}_{2}$ dielectric layer (capacitance: $37 \mathrm{pF}$ $\mathrm{m}^{-1}$ ). Moreover, due to the lower density of electronic states in the quasi-1D nanotubes in comparison to bulk semiconductors, the so-called quantum capacitance $\left(400 \mathrm{pF} \mathrm{m}^{-1}\right)$ has to be taken into account as an additional component that occurs in series with the geometrical capacitance ${ }^{60}$ The smaller of the two capacitances dominates the net capacitance. In the back-gate configuration, the capacitance is mainly governed by the dielectric capacitance, whereas for the liquid-gate the capacitance is mainly determined by the quantum capacitance.

\subsection{Conductance monitoring}

The ability to monitor the conductance of a nanotube while varying the voltage at the RE has beneficial consequences. In
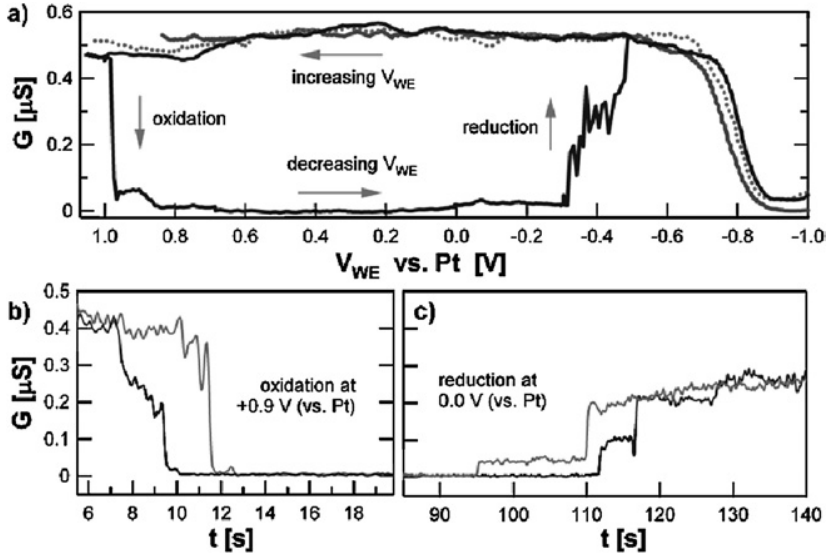

Fig. 9 (a) Conductance of a single s-SWCNT as a function of the liquidgate voltage in the presence (black solid line) and absence (dark-gray solid and light-gray dotted lines) of $\mathrm{H}_{2} \mathrm{SO}_{4}$. The dark-gray and lightgray curves are measured in water before and after the measurement in $\mathrm{H}_{2} \mathrm{SO}_{4}$. It is apparent that oxidation results in a flat zero conductance until the voltage exceeds the reduction threshold $\left(V_{\mathrm{WE}}<0 \mathrm{~V}\right)$, where the conductance of the tube is restored. (b) and (c) Measurement of the tube conductance as a function of time revealing sharp steps under oxidizing and reducing electrochemical conditions, respectively (Adapted with permission from ref. 73.)

particular, by adding an appropriate coupling agent, the conductance of the tube can be used as a sensitive indicator to trace the formation of covalent bonds to its sidewall. This was first demonstrated by observing the effect of reversible electrochemical oxidation and reduction on the conductance of individual s-SWCNTs in $\mathrm{H}_{2} \mathrm{SO}_{4}{ }^{73}$ Fig. 9 compares the conductance of such an s-SWCNT-EC-FET as a function of the voltage applied to the RE with and without $\mathrm{H}_{2} \mathrm{SO}_{4}$. In the presence of $\mathrm{H}_{2} \mathrm{SO}_{4}$, the oxidation of the tube causes a large conductance decrease, and the subsequent reduction almost completely restores the original conductance. Later experiments with the addition of a strongly oxidizing agent $\left(\mathrm{KMnO}_{4}\right)$ have even enabled the detection of point-functionalization at individual defect sites on an individual SWCNT. ${ }^{74}$ Thus, it is possible to control the degree of covalent functionalization of the tube by stopping the electrochemical modification at a desired conductance. ${ }^{144}$

It is worthwhile taking a look at the various experimental set-ups used for in situ monitoring of the conductance of the nanotubes. Strictly speaking, in addition to WE and RE, a third electrode $(\mathrm{CE})$ is necessary in order to ensure that the required potential is maintained between the WE and RE. Normally the current supplied by the $\mathrm{CE}$ is controlled in order to maintain this potential difference. However, many experiments have been carried out without the CE. ${ }^{64,75,79,92,145}$ Such a two-electrode configuration is justified by considering the fact that the intrinsic capacitance of the nanotube (quantum capacitance) is much smaller than the double layer capacitance ${ }^{\mathbf{1 4 6}}$ as a result of which the potential drop is mainly associated with shifting the electrochemical potential of the nanotube. ${ }^{60}$ By contrast, the choice of the reference electrode is probably more critical. Although Ag/ $\mathrm{AgCl}$ is principally the best-suited RE for low-volume applications, the use of $\mathrm{Pt}$ as a pseudo-reference has also resulted in consistent measurements. ${ }^{73,74}$ 


\subsection{Selective functionalization}

From the foregoing discussion and from Fig. 8, it is evident that an $\mathrm{m}$-SWCNT is amenable to electron transfer over a broad range of applicable potentials. By contrast, due to the band gap of an s-SWCNT, there exists a potential range in which electron transfer is blocked. This difference becomes directly apparent from the theoretically calculated electrochemical charge transfer rates of prototype metallic and semiconducting tubes. ${ }^{143}$ These calculations predict that by optimizing the electrochemical conditions including the type of diazonium salt used and the applied potential, it is possible to obtain a reduction rate at an m-SWCNT that is four orders of magnitude larger than at an s-SWCNT. Experiments on individual $\mathrm{m}$ - and s-SWCNTs with in situ conductance monitoring data support this prediction. ${ }^{143}$ This opens access to semiconducting networks of SWCNTs, just by performing a single electrochemical modification step. ${ }^{10}$

\section{Sensors}

Due to their high surface area and chemical stability, CNTs are close-to-ideal components of nanoscale sensors. As another advantage, which is particularly relevant for biosensing applications, the small size of CNTs enables them to access the interior of redox enzymes. ${ }^{69,70,147}$

\subsection{Gas sensors}

The sensitive detection of different types of gas molecules has been accomplished using both individual $\mathrm{CNTs}^{148}$ and thin CNT networks. ${ }^{149,150}$ Various approaches have been followed to enhance the sensitivity, selectivity and/or response time of the sensors via chemical modification. ${ }^{151,152}$ Among these, electrochemical methods have been utilized to decorate CNTs with noble metal nanoparticles ${ }^{153-156}$ or organic polymers. ${ }^{157,158}$ Oxidatively treated SWCNTs modified by electrodeposition of palladium particles exhibited a sensitive response towards hydrogen at room temperature, with a lower detection limit of $100 \mathrm{ppm}$, a linear response up to $1000 \mathrm{ppm}$, and a response time of several minutes. ${ }^{154}$ The enhanced sensitivity of such chemiresistors can be attributed to the dissociation of hydrogen atoms at the $\mathrm{Pd}-$ nanotube interface, which decreases the particle's work function and allows electrons to be transferred onto the p-type tube. ${ }^{153}$ Another chemiresistor-type gas sensor was obtained by electrochemically coating oxidized SWCNTs with polyaniline, which enabled a detection limit of $50 \mathrm{ppb}$ for ammonia at room temperature (Fig. 10). ${ }^{157}$

\subsection{Chemical sensing of (bio)molecules}

5.2.1 Electrochemical sensors. Numerous amperometric and voltammetric sensors have been realized on the basis of covalent or non-covalent linkage of appropriate modifying molecules (e.g., enzymes, DNA) to CNTs in order to improve their electroanalytical response. In the vast majority of these studies, the attachment was carried out using solution-based chemical modification protocols ${ }^{159}$ involving direct adsorption, ${ }^{160}$ amide or ester couplings to surface carboxyl groups on the tubes, ${ }^{161-163}$ or a 'mixed' approach wherein a suitable linker molecule is

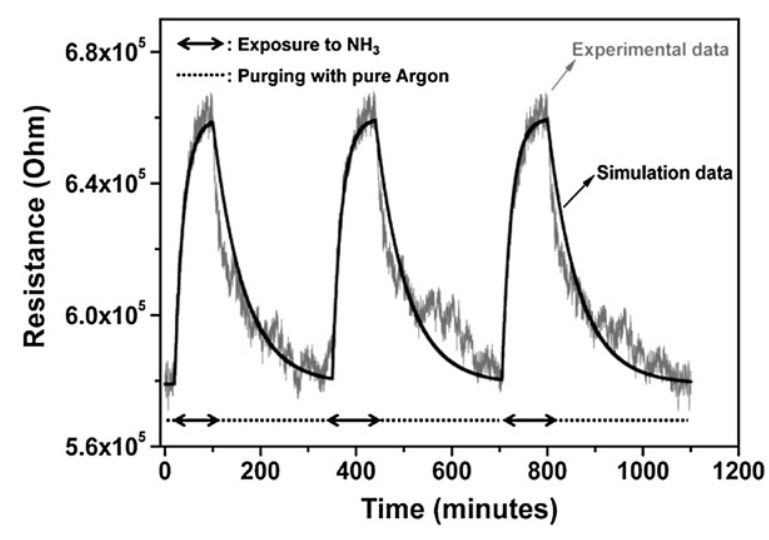

Fig. 10 Time course of electrical resistance of a gas sensor obtained by electrodeposition of polyaniline onto a SWCNT film upon exposure to ammonia $(10 \mathrm{ppm})$ at room temperature (exposure periods are indicated be the arrows). The bold line represents a fit obtained by assuming a simple first order adsorption-desorption kinetic model. (Adapted with permission from ref. 157.)

initially adsorbed onto the nanotubes, followed by covalent linkage of the (bio)molecules. ${ }^{164}$ During the past 2-3 years, increasing efforts have been directed towards utilizing electrochemical methods for the immobilization of (bio)molecules onto CNT electrodes. The employed strategies can be classified into three categories.

The first category encompasses two closely related methods, namely the electropolymerization of monomers onto CNTs and the co-electrodeposition of CNT-polymer composites (compare Sections 3.4.1 and 3.4.3). Monomers utilized for this purpose include aniline, ${ }^{165-171}$ pyrrole,${ }^{172-175}$ diphenylamine, ${ }^{176}$ 3,3'-diamino-benzidine, ${ }^{177}$ 2,6-pyridinedicarboxylic acid, ${ }^{178}$ and dye molecules like nile blue, ${ }^{179}$ neutral red $^{180}$ or substituted metallo-phthalocyanines. ${ }^{181}$ To implement specific biosensor function, different enzymes have been deposited onto or entrapped within the polymer matrix, including alcohol dehydrogenase, ${ }^{179}$ horseradish polymerase, ${ }^{170}$ choline oxidase,,${ }^{167}$ glutamate dehydrogenase, ${ }^{174}$ and glucose oxidase. ${ }^{165,172,173,177}$ Chemical pre-modification of the nanotubes, e.g., with carboxylic groups, has proven to be an effective means to improve the coupling to the formed polymer. ${ }^{166,168,172-176,178,180}$ Moreover, the sensitivity of a MWCNT-based dopamine sensor could be enhanced by the incorporation of cyclodextrin, ${ }^{169}$ which was assumed to form a supramolecular complex with the analyte.

Within the second category, organic residues like aliphatic diamines or substituted phenyl groups were first electrochemically grafted to the CNTs, followed by chemical linking of biopolymers such as double-stranded DNA ${ }^{182}$ or enzymes ${ }^{183}$ to the created functional surface groups. Sensors obtained in this manner enabled for instance the detection of DNA intercalation by dye molecules. ${ }^{182}$

The third category comprises the electrodeposition of metal nanoparticles onto CNTs, with the aim of increasing the surface area of the electrodes and/or exploiting the electrocatalytic activity of noble metals (e.g., Pt or Au-Pt alloy). ${ }^{184-186}$ In order to ensure a controlled electrochemical growth of well-defined particles, the CNTs were pre-modified via oxidation or 
adsorption of charged polyelectrolytes. Glucose sensors could then be realized through direct or indirect attachment of glucose oxidase to the metal particles.

5.2.2 Chemiresistors. Chemiresistors are devices whose resistance is directly proportional to the chemical or biological input (analyte concentration). Their active components are most commonly metal oxides used for gas sensing, ${ }^{187}$ albeit chemiresistors for application in liquid phase gain increasing importance. One example is a composite polymer chemiresistor, where analytes cause swelling and in turn an increase in resistance. ${ }^{188} \mathrm{CNT}$ s are suitable dopants for such polymer matrices, as exemplified by the fabrication of a micro-gap chemiresistor with MWCNTs incorporated into electropolymerized polypyrrole. ${ }^{189}$ This sensor exhibited a linear response to $\mathrm{H}_{2} \mathrm{O}_{2}$ and could be extended to detect glucose by incorporating glucose oxidase. In general, while chemiresistors are advantageous because they do not require a reference electrode or electron mediators, they suffer from problems such as the need for frequent calibration.

CNTs are excellently suited for the miniaturization of chemiresistors. Since the device resistance is a key-factor in such devices, m-SWCNTs are normally chosen due to their higher conductance (in comparison to their semiconducting counterparts), which remains fairly constant as a function of gate-voltage. For sensor implementation, analyte-sensitive functional groups need to be coupled onto the surface of the $\mathrm{m}$-SWCNTs. Furthermore, the functionalization degree needs to be controllable so that the tube is not completely destroyed. ${ }^{52}$ All these requirements are granted by the electrochemical covalent modification method with the in situ conductance monitoring capability, ${ }^{144}$ as demonstrated by the fabrication of a $\mathrm{pH}$ sensor through controlled covalent attachment of diethylaniline moeities to individual m-SWCNTs. ${ }^{92}$ Fig. 11 shows a typical calibration curve obtained from such an electrochemically functionalized m-SWCNT device. Protonation-dependent charge carrier scattering exerted by the appended aniline moieties is a plausible mechanism for the observed $\mathrm{pH}$ dependence of conductance. A rough analogy is molecular adsorption onto ultrathin metal films, which alters the strength of inelastic scattering of charge carriers at the film surface. ${ }^{190}$

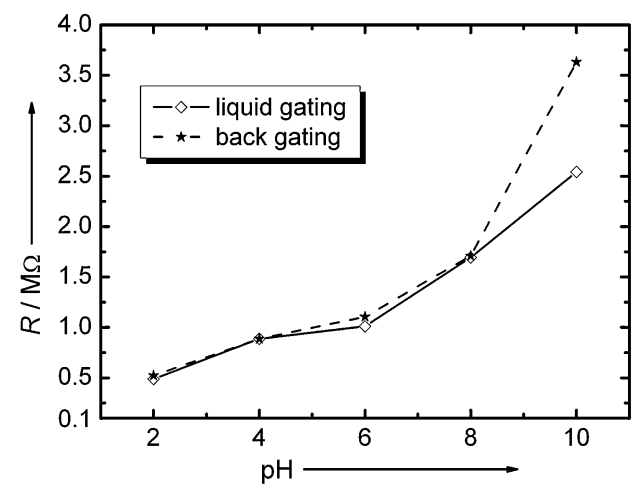

Fig. 11 Resistance as a function of $\mathrm{pH}$ for an individual m-SWCNT after electrochemical grafting of covalently bonded diethylaniline moieties. (Adapted with permission from ref. 92.)
5.2.3 Sensors based on electrochemical field-effect. The most common sensor type based upon the electrical field-effect is the Ion-Sensitive or Ion-Selective FET (ISFET). ${ }^{191}$ It comprises an active layer coated onto a gate electrode that is in contact with the liquid and whose potential is set with respect to a reference electrode. Depending on the concentration of the analyte the surface charge on the active layer varies, leading to a threshold voltage shift in the FET characteristics. However, with CNTs a different approach is being followed, as in this case the s-SWCNT acting as the channel is the active layer, and the solution is used as a gating medium (see previous section). As an example, the sensing of ammonia in liquids has been demonstrated using an s-SWCNT-EC-FET. ${ }^{192}$ Increasing concentrations of ammonia led to stronger electron doping of the nanotube resulting in a negative threshold voltage shift of the transfer characteristics. Also the hysteresis and the sub-threshold slope of such a device can be used to determine the analyte concentration. ${ }^{193}$

The characteristics of electrochemically gated unmodified s-SWCNTs have been studied as a function of $\mathrm{pH}$ and the concentration of supporting electrolytes. ${ }^{145}$ The FETs exhibited a pronounced dependence of threshold voltage shift on the $\mathrm{pH}$, whereas the transconductance and sub-threshold swing remained almost unaffected. The threshold voltage shift of the transistors increased with rising $\mathrm{pH}$, as shown in Fig. 12. Control experiments evidenced that this shift does not result from a direct charge transfer to the tube, but is most likely due to the presence of surface charges associated with carboxylate groups on the SWCNTs that become protonated at low $\mathrm{pH}$ values. Interestingly, high ionic strengths were found to screen out the surface charges, leading to a reduced threshold voltage shift. Meanwhile, a number of other sensors have been demonstrated with pristine s-SWCNTs on the basis of the electrochemical field-effect. ${ }^{193}$ In order to attain sensitivity to a certain analyte, a charge transfer promoting mediator has to be immobilized onto the tube. ${ }^{194}$ This task can be performed by several methods including electrochemistry. For example, a sensor for heavy metal ions has been obtained by electropolymerization of pyrrole- or aniline-coupled peptides onto individual s-SWCNTs in a non-covalent manner. ${ }^{195}$ After the deposition of a thick polymer coating

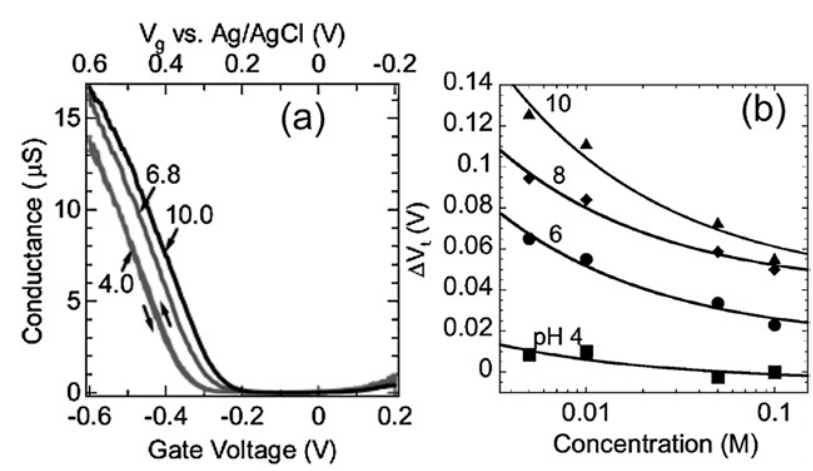

Fig. 12 (a) Liquid-gate dependence of conductance of an individual s-SWCNT at the indicated $\mathrm{pH}(10 \mathrm{mM} \mathrm{KCl})$. Both forward and reverse scans are shown for $\mathrm{pH}$ 4. (b) Concentration-dependent threshold voltage shift at the indicated $\mathrm{pH}$. The plotted threshold voltage shifts are measured with respect to the threshold voltage at $100 \mathrm{mM}$ at $\mathrm{pH} 4$. (Adapted with permission from ref. 145.) 
(>100 nm thickness), a large positive threshold shift was observed in the devices. When exposed to metal ions like $\mathrm{Ni}^{2+}$ or $\mathrm{Cu}^{2+}$, the modified s-SWCNT-EC-FETs exhibited a negative threshold voltage shift, with a magnitude proportional to the ion concentration. Selectivity towards a specific heavy metal ion could be achieved through tailored peptide sequences that chelate with the desired ion. It is well documented that peptide sequences, such as (His) ${ }_{6}$ for $\mathrm{Ni}^{2+}$, are able to form metal complexes in a very selective manner. ${ }^{195}$ A mechanism was proposed in which the initial positive threshold shift is brought about by the positive charges in the electrodeposited polymer. In the presence of metal ions, the involved groups within the polymer partake in the chelation, which shifts the threshold voltage more towards the situation of an unmodified tube.

\section{Future perspectives}

The available literature clearly witnesses that electrochemically modified CNTs have a strong application potential in various fields, most prominently biosensing. The advent of advanced electrochemical functionalization protocols in the future could enable the fabrication of high density individually addressable nanosensor arrays, in which each element is differently modified. ${ }^{196}$ Another promising perspective is the further development of novel detection principles, for example based upon a low density of surface functional groups covalently anchored to metallic nanotubes. ${ }^{92,145}$ On this basis, it may even become possible to amplify a small number of molecular events into detectable electrical signals. A related application is the use of modified CNTs as nanoscale probes for fluid flow. First results along this direction have already been obtained with pristine nanotubes. ${ }^{197,198}$

Due to their high chemical stability, low mass and large surface area, CNTs are also of strong interest for energy storage-related applications like super-capacitors, rechargeable batteries and hydrogen storage. Efficient electrochemical capacitors from pristine SWCNTs and MWCNTs have been demonstrated, ${ }^{199,200}$ and first steps towards improving their performance by electrochemical functionalization achieved. ${ }^{201}$ For example, the pore size distribution of MWCNT-based electrodes could be increased through electrochemical oxidation by up to $200 \%,{ }^{202}$ imparting a two- to three-fold increase in capacitance. Alternatively, the electrodeposition of poly ( $N$-vinyl-carbazole) proved beneficial for this purpose. ${ }^{103}$ The same type of polymer coating has furthermore enabled improvements in the performance of CNT-based lithium batteries. ${ }^{102}$ Moreover, the hydrogen storage properties of CNTs could be enhanced via electrochemical functionalization, specifically through opening the edges of MWCNTs by electrochemical oxidation in $\mathrm{H}_{2} \mathrm{SO}_{4} \cdot{ }^{203}$

Finally, membranes composed of aligned MWCNTs constitute valuable artificial platforms for mimicking selective chemical transport through biological membranes. ${ }^{204}$ The attachment of suitable molecules to the nanotube channels has allowed control of the flux of ions through such membranes. ${ }^{205}$ More recently, electrochemistry has been used to selectively tether charged molecules close to the CNT tip entrances, yielding CNT-based voltage-gated membranes. ${ }^{206}$

\section{References}

1 J. M. Bonard, N. Weiss, H. Kind, T. Stoeckli, L. Forro, K. Kern and A. Chatelain, Adv. Mater., 2001, 13, 184.

2 S. S. Wong, E. Joselevich, A. T. Woolley, C. L. Cheung and C. M. Lieber, Nature, 1998, 394, 52.

3 S. J. Tans, M. H. Devoret, H. Dai, A. Thess, R. E. Smalley, L. J. Geerligs and Cees Dekker, Nature, 1998, 386, 474.

4 R. Martel, T. Schmidt, H. R. Shea, T. Hertel and P. Avouris, Appl. Phys. Lett., 1998, 73, 2447.

5 Ph. Avouris, Z. Chen and V. Perebeinos, Nat. Nanotechnol., 2007, 2, 605.

6 A. Das, A. K. Sood, A. Govindaraj, A. M. Saitta, M. Lazzeri, F. Mauri and C. N. R. Rao, Phys. Rev. Lett., 2007, 99, 136803.

7 J. C. Tsang, M. Freitag, V. Perebeinos, J. Liu and Ph. Avouris, Nat. Nanotechnol., 2007, 2, 725.

8 M. Strano, C. A. Dyke, M. L. Usrey, P. W. Barone, M. J. Allen, H. Shan, C. Kittrell, R. H. Hauge, J. M. Tour and R. E. Smalley, Science, 2003, 301, 1519.

9 H. M. So, B. K. Kim, D. W. Park, B. S. Kim, J. J. Kim, K. J. Kong, H. Chang and J. O. Lee, J. Am. Chem. Soc., 2007, 129, 4866.

10 K. Balasubramanian, E. J. H. Lee, R. T. Weitz, M. Burghard and K. Kern, Phys. Status Solidi B, DOI: 10.1002/pssa.200723410.

11 M. Burghard, Surf. Sci. Rep., 2005, 58, 1.

12 R. Saito, G. Dresselhaus and M. S. Dresselhaus, Physical Properties of Carbon Nanotubes, Imperial College Press, London, 1998.

13 J. W. G. Wilder, L. C. Venema, A. G. Rinzler, R. E. Smalley and C. Dekker, Nature, 1998, 391, 59.

14 M. Zheng and E. D. Semke, J. Am. Chem. Soc., 2007, 129, 6084.

15 A. Nish, J. Y. Hwang, J. Doig and R. J. Nicholas, Nat. Nanotechnol., 2007, 2, 640.

16 F. Chen, B. Wang, Y. Chen and L. J. Li, Nano Lett., 2007, 7, 3013.

17 X. Peng, N. Komatsu, S. Bhattacharya, T. Shimawaki, S. Aonuma, T. Kimura and A. Osuka, Nat. Nanotechnol., 2007, 2, 361.

18 E. V. Basiuk, M. Monroy-Pelaez, I. Puente-Lee and V. A. Basiuk, Nano Lett., 2004, 4, 863.

19 K. Lee, L. Li and L. Dai, J. Am. Chem. Soc., 2005, 127, 4122.

20 M. D'Este, M. D. Nardi and E. Menna, Eur. J. Org. Chem., 2006, 11, 2517.

$21 \mathrm{X} . \mathrm{Lu}$ and Z. Chen, Chem. Rev., 2005, 105, 3643.

22 W. H. Lee, S. J. Kim, W. J. Lee, J. G. Lee, R. C. Haddon and P. J. Reucroft, Appl. Surf. Sci., 2001, 181, 121.

$23 \mathrm{H}$. Hu, B. Zhao, M. A. Hamon, K. Kamaras, M. E. Itkis and R. C. Haddon, J. Am. Chem. Soc., 2003, 125, 14893.

24 V. Georgakilas, K. Kordatos, M. Prato, D. M. Guldi, M. Holzinger and A. Hirsch, J. Am. Chem. Soc., 2002, 124, 760.

25 Z. L. Yao, N. Braidy, G. A. Botton and A. Adronov, J. Am. Chem. Soc., 2003, 125, 16015.

26 W. Zhou, Y. H. Ooi, R. Russo, P. Papanek, D. E. Luzzi, J. E. Fischer, M. J. Bronikowski, P. A. Willis and R. E. Smalley, Chem. Phys. Lett., 2001, 350, 6.

27 M. Yudasaka, M. Zhang and S. Iijima, Chem. Phys. Lett., 2003, 374, 132.

28 F. Simon, A. Kukowecz, C. Kramberger, R. Pfeiffer, F. Hasi, H. Kuzmany and H. Kataura, Phys. Rev. B, 2005, 71, 165439.

29 S. Niyogi, M. A. Hamon, H. Hu, B. Zhao, P. Bhowmik, R. Sen, M. E. Itkis and R. C. Haddon, Acc. Chem. Res., 2002, 35, 1105.

30 Z. Chen, W. Thiel and A. Hirsch, ChemPhysChem., 2003, 4, 93.

31 G. Zheng, Z. Wang, S. Irle and K. Morokuma, J. Am. Chem. Soc., 2006, 128, 15117.

32 F. H. Yang, A. J. Lachawiec and R. T. Yang, J. Phys. Chem. B, $2006,110,6236$

33 J. Li, G. Jia and Y. Zhang, Chem.-Eur. J., 2007, 13, 6430.

34 Y. Miyata, Y. Maniwa and H. Kataura, J. Phys. Chem. B, 2006, 110, 25.

35 S. Banerjee and S. S. Wong, J. Am. Chem. Soc., 2004, 126, 2073.

36 E. Joselevich, ChemPhysChem., 2004, 5, 619.

37 J. Lu, L. Lai, G. Luo, J. Zhou, R. Qin, D. Wang, L. Wang, W. N. Mei, G. Li, Z. Gao, S. Nagase, Y. Maeda, T. Akasaka and D. Yu, Small, 2007, 3, 1566.

38 K. A. Shiral Fernando, Y. Lin, W. Wang, L. Cao, M. J. Meziani, X. Wang, M. L. Veca, P. Zhang, R. A. Quinn, L. F. Allard and Y. P. Sun, J. Phys. Chem. C, 2007, 111, 10254.

39 T. C. Dinadayalane, A. Kaczmarek, J. Lukaszewicz and J. Leszczynski, J. Phys. Chem. C, 2007, 111, 7376.

40 A. Kaczmarek, J. Comput. Chem., 2007, 107, 2211. 
41 E. Clar, Polycyclic Hydrocarbons, Academic Press, New York 1964. 42 J. L. Ormsby and B. T. King, J. Org. Chem., 2007, 72, 4035.

43 M. W. Zhao, Y. Xia, J. P. Lewis and L. Mei, J. Phys. Chem. B, 2004, 108, 9599.

44 L. V. Liu, Wei Quan Tian and Yan Alexander Wang, J. Phys. Chem. $B, 2006,110,1999$.

45 L. V. Liu, W. Q. Tian and Y. A. Wang, J. Phys. Chem. B, 2006, 110, 13037

46 C. C. Wang, G. Zhou, H. Liu, J. Wu, Y. Qiu, B. L. Gu and W. Duan, J. Phys. Chem. B, 2006, 110, 10266.

47 M. Monthioux, Carbon, 2002, 40, 1809.

48 H. F. Bettinger, J. Phys. Chem. B, 2005, 109, 6922

49 T. C. Dinadayalane and J. Leszczynski, Chem. Phys. Lett., 2007 , 434, 86

50 X. Lu, Z. Chen and P. v. R. Schleyer, J. Am. Chem. Soc., 2005, 127, 20

51 G. Zheng, Q. Li, K. Jiang, X. Zhang, J. Chen, Z. Ren and S. Fan, Nano Lett., 2007, 7, 1622.

52 K. Balasubramanian, M. Friedrich, C. Jiang, Y. Fan, A. Mews, M. Burghard and K. Kern, Adv. Mater., 2003, 15, 1515

53 J. Cabana and R. Martel, J. Am. Chem. Soc., 2007, 129, 2244.

54 A. J. Du and S. C. Smith, Mol. Simul., 2006, 32, 1213.

55 F. Mercuri and A. Sgamellotti, Inorg. Chim. Acta, 2007, 360, 785.

56 M. V. Veloso, A. G. Souza Filho, J. Mendes Filho, Solange B. Fagan and R. Mota, Chem. Phys. Lett., 2006, 430, 71.

57 E. Cho, H. Kim, C. Kim and S. Han, Chem. Phys. Lett., 2006, 419, 134

58 Y. S. Lee and N. Marzari, Phys. Rev. Lett., 2006, 97, 116801.

59 T. Umeyama, N. Tezuka, M. Fujita, Y. Matano, N. Takeda, K. Murakoshi, K. Yoshida, S. Isoda and H. Imahori, J. Phys Chem. C, 2007, 111, 9734 .

60 S. Rosenblatt, Y. Yaish, J. Park, J. Gore, V. Sazonova and P. L. McEuen, Nano Lett., 2002, 2, 869.

61 A. Chou, T. Boecking, N. K. Singh and J. J. Gooding, Chem. Commun., 2005, 842 .

62 C. E. Banks, T. J. Davies, G. G. Wildgoose and R. G. Compton, Chem. Commun., 2005, 829

63 J. K. Campbell, L. Sun and R. M. Crooks, J. Am. Chem. Soc., 1999, 121, 3779.

64 I. Heller, J. Kong, H. A. Heering, K. A. Williams, S. G. Lemay and C. Dekker, Nano Lett., 2005, 5, 137.

$65 \mathrm{~K}$. Balasubramanian, M. Burghard and K. Kern, Carbon Nanotubes: Electrochemical Modification, in Dekker Encyclopedia of Nanoscience and Nanotechnology, ed. J. A. Schwarz, C. I. Contescu and K. Puteyra, New York, Marcel Dekker, 2004.

66 A. G. Rinzler, J. Liu, H. Dai, P. Nikolaev, C. B. Huffman, F. J. Rodriguesmacias, P. J. Boul, A. H. Lu, D. Heymann, D. T. Colbert, R. S. Lee, J. E. Fisher, A. M. Rao, P. C. Eklund and R. E. Smalley, Appl. Phys. A, 1998, 67, 29.

67 C. Y. Liu, A. J. Bard, F. Wudl, I. Weitz and J. R. Heath, Electrochem. Solid-State Lett., 1999, 2, 577.

68 J. J. Gooding, A. Chou, J. Liu, D. Losic, J. G. Shapter and D. B. Hibbert, Electrochem. Commun., 2007, 9, 1677.

69 J. J. Gooding, R. Wibowo, J. Liu, W. Yang, D. Losic, S. Orbons, F. J. Mearns, J. G. Shapter and D. B. Hibbert, J. Am. Chem. Soc., 2003, 125, 9006.

70 F. Patolsky, Y. Weizmann and I. Willner, Angew. Chem., Int. Ed., 2004, 43, 2113

71 A. J. Bard and L. R. Faulkner, Electrochemical Methods: Fundamentals and Applications, Wiley, New York, 2000.

72 J. L. Bahr, J. Yang, D. V. Kosynkin, M. J. Bronikowski, R. E. Smalley and J. M. Tour, J. Am. Chem. Soc., 2001, 123, 6536.

73 J. Mannik, B. R. Goldsmith, A. Kane and P. G. Collins, Phys. Rev. Lett., 2006, 97, 016601.

74 B. R. Goldsmith, J. G. Coroneus, V. R. Khatap, A. A. Kane, G. A. Weiss and P. G. Collins, Science, 2007, 315, 77.

75 T. M. Day, P. R. Unwin, N. R. Wilson and J. V. Macpherson, J. Am. Chem. Soc., 2005, 127, 10639.

76 T. Assmus, K. Balasubramanian, M. Burghard, K. Kern, M. Scolari, N. Fu, A. Myalitsin and A. Mews, Appl. Phys. Lett., 2007, 90, 173109.

77 M. Scolari, A. Mews, N. Fu, A. Myalitsin, T. Assmus, K. Balasubramanian, M. Burghard and K. Kern, J. Phys. Chem. C, 2008, 112, 391.

78 V. Georgakilas, D. Gournis, V. Tzitzios, L. Pasquato, D. M. Guldi and M. Prato, J. Mater. Chem., 2007, 17, 2679.

79 I. Dumitrescu, N. R. Wilson and J. V. Macpherson, J. Phys Chem. C, 2007, 111, 12944
80 Y. Fan, B. R. Goldsmith and P. G. Collins, Nat. Mater., 2005, 4, 906 81 B. M. Quinn and S. G. Lemay, Adv. Mater., 2006, 18, 855

82 A. D. Franklin, J. T. Smith, T. Sands, T. S. Fisher, K. S. Choi and D. B. Janes, J. Phys. Chem. C, 2007, 111, 13756.

83 A. J. Downard, Electroanalysis, 2000, 12, 1085.

84 J. S. Ye, X. Liu, H. F. Cui, W. D. Zhang, F. S. Sheu and T. M. Lim, Electrochem. Commun., 2005, 7, 249.

85 X. R. Ye, L. H. Chen, C. Wang, J. F. Aubuchon, I. C. Chen, A. I. Gapin, J. B. Talbot and S. Jin, J. Phys. Chem. B, 2006, 110, 12938.

86 C. M. Liu, H. B. Cao, Y. P. Li, H. B. Xu and Y. Zhang, Carbon, 2006, 44, 2919.

87 Y. Wang, S. V. Malhotra, F. J. Owens and Z. Iqbal, Chem. Phys Lett., 2005, 407, 68.

88 A. Zuttel, Ch. Nuetzenadel, P. Sudan, Ph. Mauron, Ch. Emmenegger, S. Rentsch, L. Schlapbach, A. Weidenkaff and T. Kiyobayashi, J. Alloys Compd., 2002, 330, 676.

89 E. Unger, A. Graham, F. Kreupl, M. Liebau and W. Hoenlein, Curr. Appl. Phys., 2002, 2, 107

90 M. Musameh, N. S. Lawrence and J. Wang, Electrochem. Commun., $2005,7,14$

91 P. R. Marcoux, P. Hapiot, P. Batail and J. Pinson, New J. Chem., 2004, 28, 302

92 A. Maroto, K. Balasubramanian, M. Burghard and K. Kern, ChemPhysChem, 2007, 8, 220.

93 M. M. Waje, X. Wang, W. Li and Y. Yan, Nanotechnology, 2005, 16, S395.

94 T. Matrab, J. Chancolon, M. Mayne L'hermite, J. N. Rouzaud, G. Deniau, J. P. Boudou, M. M. Chehimi and M. Delamar, Colloids Surf., A, 2006, 287, 217.

95 M. A. Alonso-Lomillo, O. Ruediger, A. Maroto-Valiente, M. Velez, I. Rodríguez-Ramos, F. J. Munoz, V. M. Fernandez and A. L. DeLacey, Nano Lett., 2007, 7, 1603.

96 C. S. Lee, S. E. Baker, M. S. Marcus, W. Yang, M. A. Eriksson and R. J. Hamers, Nano Lett., 2004, 4, 1713.

97 M. Baibarac, I. Baltog, C. Godon, S. Lefrant and O. Chauvet, Carbon, 2004, 42, 3143.

98 D. Wei, C. Kvarnstrom, T. Lindfors and A. Ivaska, Electrochem. Commun., 2007, 9, 206.

99 R. Petrov, X. Lou, C. Pagnoulle, C. Jérôme, C. Calberg and R. Jérôme, Macromol. Rapid Commun., 2004, 25, 987.

100 G. Gao, D. Guo, C. Wang and H. Li, Electrochem. Commun., 2007, 9, 1582.

101 Y. Zhang, Y. Shen, J. Li, L. Niu, S. Dong and A. Ivaska, Langmuir, 2005, 21, 4797.

102 M. Baibarac, M. Lira-Cantu, J. Oro-Sole, N. Casan-Pastor and P. Gomez-Romero, Small, 2006, 2, 1075.

103 M. Baibarac, P. Gomez-Romero, M. Lira-Cantu, N. Casan-Pastor, N. Mestres and S. Lefrant, Eur. Polym. J., 2006, 42, 2302.

104 M. Gao, S. Huang, L. Dai, G. Wallace, R. Gao and Z. Wang, Angew. Chem., Int. Ed., 2000, 39, 3664.

105 J. E. Huang, X. H. Li, J. C. Xu and H. L. Li, Carbon, 2003, 41, 2731.

106 Y. K. Zhou, B. L. He, W. J. Zhou and H. L. Li, J. Electrochem. Soc., 2004, 151, A1052.

107 K. H. An, K. K. Jeon, J. K. Heo, S. C. Lin, D. J. Bae and Y. H. Lee, J. Electrochem. Soc., 2002, 149, A1058.

108 J. H. Chen, Z. P. Huang, D. Z. Wang, S. X. Yang, J. G. Wen and Z. F. Ren, Appl. Phys. A, 2001, 73, 129.

109 P. Gajendran and R. Saraswathi, J. Phys. Chem. C, 2007, 111, 11320

110 L. Valentini, F. Mengoni, L. Mattiello and J. M. Kenny, Nanotechnology, 2007, 18, 115702.

111 Y. Diamant, J. Chen, H. Han, B. Kamenev, L. Tsybeskov and H. Grebel, Synth. Met., 2005, 151, 202.

112 J. H. Chen, Z. P. Huang, D. Z. Wang, S. X. Yang, W. Z. Li, J. G. Wen and Z. F. Ren, Synth. Met., 2002, 125, 289.

113 A. Hassanien, M. Gao, M. Tokumoto and L. Dai, Chem. Phys. Lett., 2001, 342, 479.

114 P. Soundarrajan, A. Patil and L. Dai, J. Vac. Sci. Technol., A, 2003, 21, 1198.

115 L. Valentini, V. Bavastrello, E. Stura, I. Armentano, C. Nicolini and J. M. Kenny, Chem. Phys. Lett., 2004, 383, 617.

116 T. Defever, G. Deniau, S. Palacin, L. Goux-capes, S. Barrau, M. Mayne-l'hermite and J.-P. Bourgoin, J. Electroanal. Chem., 2006, 589, 46.

117 S. E. Kooi, U. Schlecht, M. Burghard and Kern, Angew. Chem., Int. Ed., 2002, 41, 1353 
118 Y. Kang and D. Kim, Sens. Actuators, A, 2006, 125, 114.

119 Z. Li, J. Chen, W. Li, K. Chen, L. Nie and S. Yao, J. Electroanal Chem., 2007, 603, 59.

120 J. S. Ye, Y. Wen, W. D. Zhang, H. F. Cui, C. Q. Xiu and F. S. Sheu, Nanotechnology, 2006, 17, 3994.

121 G. Z. Chen, M. S. P. Shaffer, D. Coleby, G. Dixon, W. Zhou, D. J. Fray and A. H. Windle, Adv. Mater., 2000, 12, 522.

122 M. Wu, G. A. Snook, V. Gupta, M. Shaffer, D. J. Fray and G. Z. Chen, J. Mater. Chem., 2002, 15, 2297.

123 M. Hughes, G. Z. Chen, M. S. P. Shaffer, D. J. Fray and A. H. Windle, Chem. Mater., 2002, 14, 1610.

124 J. Wang, J. Dai and T. Yarlagadda, Langmuir, 2005, 21, 9.

125 X. Zhang, J. Zhang and Z. Liu, Carbon, 2005, 43, 2186.

126 X. Zhang, W. Song, P. J. F. Harris and G. R. Mitchell, ChemPhysChem, 2007, 8, 1766.

127 G. Han, J. Yuan, G. Shi and F. Wei, Thin Solid Films, 2005, 474, 64

128 E. Granot, B. Basnar, Z. Cheglakov, E. Katz and I. Willner, Electroanalysis, 2006, 18, 26.

129 K. M. Manesh, P. Santhosh, A. I. Gopalan and K. P. Lee, Electroanalysis, 2006, 18, 1564

130 P. Santhosh, A. Gopalan and K. P. Lee, J. Catal., 2006, 238, 177.

131 A. K. Wanekaya, Y. Lei, E. Bekyarova, W. Chen, R. Haddon, A. Mulchandani and N. V. Myung, Electroanalysis, 2006, 18, 1047.

132 B. Philip, Smart Mater. Struct., 2004, 13, N105.

133 B. Zhao, H. Hu and R. C. Haddon, Adv. Funct. Mater., 2004, 14 71.

134 B. Philip, J. Xie, J. K. Abraham and V. K. Varadan, Polym. Bull., $2005, \mathbf{5 3}, 127$.

135 H. Zhang, H. X. Li and H. M. Cheng, J. Phys. Chem. B, 2005, 110, 9095.

136 J. Zeng, W. Wei, L. Wu, X. Liu, K. Liu and Y. Li, J. Electroanal. Chem., 2006, 595, 152.

137 X. L. Luo, J. J. Xu, J. L. Wang and H. Y. Chen, Chem. Commun., 2005, 2169.

138 Y. Yang, L. Qu, L. Dai, T. S. Kang and M. Durstock, Adv. Mater., 2007, 19, 1239

139 R. Krupke, F. Hennrich, H. v. Löhneysen and M. M. Kappes, Science, 2003, 301, 344

140 M. S. Arnold, A. A. Green, J. F. Hulvat, S. I. Stupp and M. C. Hersam, Nat. Nanotechnol., 2006, 1, 60.

141 P. G. Collins, M. S. Arnold and Ph. Avouris, Science, 2001, 292, 706.

142 K. Balasubramanian, R. Sordan, M. Burghard and K. Kern, Nano Lett., 2004, 4, 827.

143 K. Balasubramanian and M. Burghard, Phys. Chem. Chem. Phys., DOI: 10.1039/b718626f.

144 M. Burghard, A. Maroto, K. Balasubramanian, T. Assmus, A. Forment-Aliaga, E. J. H. Lee, R. T. Weitz, M. Scolari, F. Nan, A. Mews and K. Kern, Phys. Status Solidi B, 2007, 244, 4021.

145 J. H. Back and M. Shim, J. Phys. Chem. B, 2006, 110, 23736.

146 J. Wang, Analytical Electrochemistry, 3rd edn, Wiley-VCH, New Jersey, 2006.

147 X. Yu, D. Chattopadhyay, I. Galeska, F. Papadimitrakopoulos and J. F. Rusling, Electrochem. Commun., 2003, 5, 408

148 J. Kong, N. R. Franklin, C. Zhou, M. G. Chapline, S. Peng, K. Cho and H. Dai, Science, 2000, 287, 622

149 P. Vichchulada, Analyst, 2007, 132, 719

150 M. L. Terranova, J. Phys.: Condens. Matter, 2007, 19, 225004.

151 Q. F. Pengfei, O. Vermesh, M. Grecu, A. Javey, Q. Wang, H. Dai, S. Peng and K. J. Cho, Nano Lett., 2003, 3, 347

152 S. Kim, H. R. Lee, Y. J. Yun, S. Ji, K. Yoo, W. S. Yun, J. Y. Koo and D. H. Ha, Appl. Phys. Lett., 2007, 91, 093126.

153 U. Schlecht, K. Balasubramanian, M. Burghard and K. Kern, Appl. Surf. Sci., 2007, 253, 8394.

154 S. Mubeen, T. Zhang, B. Yoo, M. A. Deshusses and N. V. Myung, J. Phys. Chem. C, 2007, 111, 6321

155 Y. Sun and H. H. Wang, Appl. Phys. Lett., 2007, 90, 213107.

156 A. Star, V. Joshi, S. Skarupo, D. Thomas and J. C. P. Gabriel, J. Phys. Chem. B, 2006, 110, 21014

157 T. Zhang, M. B. Nix, B. Y. Yoo, M. A. Deshusses and N. V. Myung, Electroanalysis, 2006, 18, 1153.

158 T. Zhang, Nanotechnology, 2007, 18, 165504.

159 W. Yang, P. Thordarson, J. J. Gooding, S. P. Ringer and F. Braet, Nanotechnology, 2007, 18, 412001.

160 D. Nepal and K. E. Geckeler, Small, 2007, 3, 1259.

161 H. Cai, X. Cao, Y. Jiang, P. He and Y. Fang, Anal. Bioanal. Chem., $2003,375,287$
162 P. G. He and L. Dai, Chem. Commun., 2004, 348.

163 Y. H. Lin, F. Lu, Y. Tu and Z. Ren, Nano Lett., 2004, 4, 191.

164 R. J. Chen, Y. Zhang, D. Wang and H. Dai, J. Am. Chem. Soc., 2001, 123, 3838.

165 M. Gao, L. Dai and G. G. Wallace, Electroanalysis, 2003, 15, 1089.

166 M. Guo, J. Chen, J. Li, B. Tao and S. Yao, Anal. Chim. Acta, 2005, 532, 71 .

167 F. Qu, J. Jiang, G. Shen and R. Yu, Anal. Biochem., 2005, 344, 108

168 P. Santhosh, K. M. Manesh, A. Gopalan and K. P. Lee, Anal. Chim. Acta, 2006, 575, 32

169 T. Yin, W. Wei and J. Zeng, Anal. Bioanal. Chem., 2006, 386, 2087.

170 X. Luo, A. J. Killard, A. Morrin and M. R. Smyth, Anal. Chim. Acta, 2006, 575, 39.

171 M. Li and L. Jing, Electrochim. Acta, 2007, 52, 3250.

172 A. Callegari, S. Cosnier, M. Marcaccio, D. Paolucci, F. Paolucci, V. Georgakilas, N. Tagmatarchis, E. Vázquez and M. Prato, J. Mater. Chem., 2004, 14, 807

173 Y.-C. Tsai, S. C. Li and S. W. Liao, Biosens. Bioelectron., 2006, 22, 495.

174 L. Tang, Y. Zhu, X. Yang and C. Li, Anal. Chim. Acta, 2007, 597, 145.

175 Y. Li, P. Wang, L. Wang and X. Lin, Biosens. Bioelectron., 2007, 22, 3120.

176 P. Santhosh, K. M. Manesh, K. P. Lee and A. I. Gopalan, Electroanalysis, 2006, 18, 894.

177 K. P. Loh, S. L. Zhao and W. D. Zhang, Diamond Relat. Mater., 2004, 13, 1075

178 J. Yang, K. Jiao and T. Yang, Anal. Bioanal. Chem., 2007, 389, 913.

179 P. Du, S. Liu, P. Wu and C. Cai, Electrochim. Acta, 2007, 53, 1811.

180 U. Yogeswaran and S. M. Chen, Electrochim. Acta, 2007, 52, 5985.

181 J. Pillay and K. I. Ozoemena, Chem. Phys. Lett., 2007, 441, 72

182 H. Tang, J. Chen, K. Cui, L. Nie, Y. Kuang and S. Yao, J. Electroanal. Chem., 2006, 587, 269.

183 K. Zhao, S. Zhuang, Z. Chang, H. Songm, L. Dai, P. He and Y. Fang, Electroanalysis, 2007, 19, 1069.

184 X. Kang, Z. Mai, X. Zou, P. Cai and J. Mo, Anal. Biochem., 2007, $363,143$.

185 X. Kang, Z. Mai, X. Zou, P. Cai and J. Mo, Anal. Biochem., 2007, 369, 71 .

186 X. Chu, D. Duan, G. Shen and R. Yu, Talanta, 2007, 71, 2040.

187 G. Eranna, B. C. Joshi, D. P. Runthala and R. P. Gupta, Crit. Rev. Solid State Mater. Sci., 2004, 29, 111.

188 M. C. Lonergan, E. J. Severin, B. J. Doleman, S. A. Beaber, R. H. Grubb and N. S. Lewis, Chem. Mater., 1996, 8, 2298.

189 K.-S. Teh and L. Lin, J. Micromech. Microeng., 2005, 15, 2019.

190 G. A. Fried, Y. M. Zhang and P. W. Bohn, Thin Solid Films, 2001, 401, 171.

191 M. Kleitz, E. Siebert, P. Fabry, J. Fouletier in Sensors: a Comprehensive Survey, Vol. 2: Chemical and Biochemical Sensors, ed. W. Goepel, T. A. Jones, M. Kleitz, J. Lundstroem and T. Seiyama, Weinheim, Wiley-VCH, 1991, ch. 8, pp. 341-428.

192 K. Bradley, J. C. P. Gabriel, M. Briman, A. Star and G. Gruener, Phys. Rev. Lett., 2003, 91, 218301.

193 B. L. Allen, P. D. Kichambare and A. Star, Adv. Mater., 2007, 19, 1439.

194 K. Balasubramanian and M. Burghard, Small, 2005, 2, 180.

195 E. S. Forzani, X. Li, P. Zhang, N. Tao, R. Zhang, I. Amlani, R. Tsui and L. A. Nagahara, Small, 2006, 2, 1283.

196 Z. Q. Gao, Anal. Chem., 2007, 79, 3291.

197 S. Ghosh, A. K. Sood and N. Kumar, Science, 2003, 299, 1042.

198 B. Bourlon, J. Wong, C. Miko, L. Forro and M. Bockrath, Nat. Nanotechnol., 2007, 2, 104.

199 C. Niu, E. K. Sichel, R. Hoch, D. Moy and H. Tennet, Appl. Phys. Lett., 1997, 70, 1480.

200 K. H. An, W. S. Kim, Y. S. Park, Y. C. Hoi, S. M. Lee, D. C. Chung, D. J. Bae, S. C. Lim and Y. H. Lee, Adv. Mater., 2001, 13, 497.

201 M. Hughes, M. S. P. Shaffer, A. C. Renouf, C. Singh, G. Z. Chen, D. J. Fray and A. H. Windle, Adv. Mater., 2002, 14, 382.

202 C. G. Liu, H. T. Fang, F. Li, M. Liu and H. M. Cheng, J. Power Sources, 2006, 160, 758

203 J. M. Skowronski, P. Scharff, N. Pfaender and S. Cui, Adv. Mater., 2003, 15, 55.

204 P. Nednoor, N. Chopra, V. Gavalas, L. G. Bachas and B. J. Hinds, Chem. Mater., 2005, 17, 3595.

205 M. Majumder, N. Chopra and B. J. Hinds, J. Am. Chem. Soc., 2005, 127, 9062 .

206 M. Majumder, X. Zhan, R. Andrews and B. J. Hinds, Langmuir, $2007,23,8624$ 